\title{
The association between renal stones and fasting: A systematic review
}

\author{
Abirami Kirubarajan ${ }^{1,2}$; Andrew C.L. Lam ${ }^{1}$; Shawn Khan ${ }^{1}$; Matthew Yau ${ }^{1,2}$; Nicole Golda ${ }^{3}$; \\ Roger Buckley ${ }^{3}$ \\ ${ }^{1}$ Faculty of Medicine, University of Toronto, Toronto, ON, Canada; ${ }^{2}$ Institute of Health Policy Management and \\ Evaluation, University of Toronto, Toronto, ON, Canada; ${ }^{3}$ Urology, North York General Hospital, Toronto, ON, \\ Canada
}

Cite as: Kirubarajan A, Lam ACL, Khan S, et al. The association between renal stones and fasting: A systematic review. Can Urol Assoc J 2020 August 7; Epub ahead of print. http://dx.doi.org/10.5489/cuaj.6664

Published online August 7, 2020

$* * *$

\section{Abstract}

Introduction: Fasting is a common cultural practice worldwide for both religious and dietary reasons. However, there is concern that fasting may be a risk factor for the development of renal stones. To date, there has not been a systematic assessment of the literature regarding the association between renal stones and fasting.

Methods: We conducted a systematic review following PRISMA guidelines of three databases: Medline-OVID, EMBASE, and CINAHL. All screening and extraction was completed in parallel with two independent reviewers.

Results: Of the 1501 database citations, a total of 10 observational studies with a total of 9906 participants were included. Nine of the studies were conducted in the context of Islamic fasting during Ramadan, with the majority (7/9) finding that renal colic incidence was unaffected by the month of fasting. In contrast, two studies noted an increased incidence among fasting populations. Two other studies noted that urine metabolites and density were altered with fasting but did not translate into clinical outcomes.

Conclusions: Based on the available evidence, it is unlikely that fasting significantly increases the risk of renal stones. Physicians should counsel higher-risk patients on safe fasting practices. 


\section{Introduction}

The practice of fasting, defined as the deliberate restriction of food or water intake, has been increasingly studied in the medical literature. ${ }^{1}$ There are diverse fasting practices worldwide, varying in duration and types of permissible intake. Fasting is observed in many religions, including the Bahá'í Faith, Buddhism, Christianity, Hinduism, Islam, Jainism, and Judaism. ${ }^{2-5}$ Fasting has also traditionally been used as a method of non-violent protest. ${ }^{6}$ In the $21^{\text {st }}$ century, there has been a rising surge of interest in fasting for health purposes. Intermittent fasting is a popular weight loss diet, in which participants fast in cyclical patterns. ${ }^{7}$ For instance, followers of the "5:2 diet" restrict their caloric intake on two days of a seven day cycle. ${ }^{8}$ Studies have demonstrated metabolic benefits to fasting, including improved glycemic control, insulin sensitivity, and appetite reduction, which culminates in overall weight loss. ${ }^{2,9}$

While the short-term adverse events of fasting are well-documented and are largely related to symptoms of hypoglycemia (headaches, nausea, and lethargy), ${ }^{10}$ the long-term health outcomes remain unclear. There is particular concern that fasting may be a risk factor for the development of renal stones. Low urine volume and dehydration are both risk factors for renal stoneformation. ${ }^{11,12}$ Fasting can lead to dehydration which in turn promotes the secretion of antidiuretic hormone (ADH) and adrenocorticotropic hormone (ACTH). Both hormones reduce urine output and concentrate calcium in urine, the main precipitant of renal stones. ${ }^{13,14}$

While there have been numerous narrative reviews on the topic, there has not yet been a systematic assessment of literature. ${ }^{17,18}$ Additionally, previous reviews did not search for studies examining fasting for weight loss, including intermittent fasting or " $5: 2$ " studies. As such, a consensus on the best practices of fasting and renal stones has not been reached. ${ }^{19}$ The aim of this systematic review is to collect all available literature regarding renal stones and fasting. We aim to characterize the incidence of renal stones in fasting populations, in addition to determining the association between the duration of fasting and type of intake with renal stone formation.

\section{Methods}

This systematic review was conducted according to the standards and guidelines established by the Preferred Reporting Items for Systematic Reviews and Meta-Analysis (PRISMA) andthe fourth edition of the Joanna Briggs Institute Reviewer's Manual. ${ }^{19,20}$ We conducted a systematic literature search of three databases: Ovid MEDLINE, Ovid EMBASE, and EBSCO CINAHL plus.

We remained broad with our search criteria in order to maximize sensitivity. We searched broadly for all types of fasting and did not add specifiers to limit our yield. Our search strategy is included in the Appendix. 
We only examined original, peer-reviewed literature published in the English language. Databases were examined from their inception until March $18^{\text {th }}, 2020$.). Published conference posters, papers, and abstracts were eligible for inclusion.

Articles were excluded if they were not relevant to fasting, or did not report outcomes related to kidney stones. The definition of fasting was kept broad, including either restriction of food or water intake for any time period. Papers that self-identified as being relevant to fasting were included. Case reports, animal studies, and cadaveric studies were excluded.

\section{Study selection and extraction}

Study selection was completed in duplicate by two independent, parallel reviewers (AL, SK) for both title and abstract screening as well as full-text screening. Covidence was used for data management and screening. Data extraction was performed in duplicate by two independent investigators (AL, SK), with a third (AK) resolving discrepancies. Risk of bias assessment was graded using the RoBANS tool for non-randomized studies.

\section{Results}

\section{Search yield}

Results of the study screening process are available in the PRISMA diagram in Figure 1. Of the 1501 original database citations, 500 total duplicates were removed. After title and abstract screening, 17 were eligible for full-text evaluation. After a hand-search of relevant journals and citations, no additional studies were added. Of the 17 full-text articles, a total of 10 were included in this systematic review.

Inter-rater reliability for study screening for abstract and full-text screening was $99.2 \%$ and $94.0 \%$ respectively. The authors were in substantial agreement with a calculated $\kappa$ of 0.73 for abstract screening and 0.88 for full-text.

\section{Article characteristics}

Details of the included studies are outlined in Table 2 of the Appendix.

All 10 articles were observational studies, with the majority $(6 / 10)$ prospective in nature and the remaining four (4/10) retrospective. The majority $(9 / 10)$ of the included studies were specific to fasting during Ramadan, a Muslim holy month that involves abstinence from food and water during daytime hours. ${ }^{2}$ The remaining study was a plasmic and uric acid level study of men after a single fast for 12 hours. ${ }^{40}$ There were no studies related to intermittent fasting or other weight loss diets.

The majority of studies were located in the Middle East $(n=7)$, with the remainder located in Pakistan $(n=1)$, the United States $(n=1)$, and England $(n=1)$.

Our systematic review includes the results of 9906 fasting participants, with an average sample size of 1111 per study. Three studies included only male participants. ${ }^{35,40,41}$ 
Details of the risk of bias for each study are provided in the Appendix (Table 3). Four studies were graded as low risk of bias, while six studies were graded as intermediate to high risk. Studies were graded down due to bias in participation selection, confounding due to temperature/seasonal variation, and potential for missing data.

\section{Outcomes}

Nine studies examined the incidence of renal colic or renal stones in relation to the month of Ramadan. There were contrasting results regarding the outcomes. The majority $(n=7)$ of studies found that the risk of renal colic did not differ in non-Ramadan months or among non-fasters. ${ }^{34-}$ ${ }^{39,41}$ Emergency department visits related to renal colic were often used to calculate the number of renal stone diagnoses. One study specifically assessed the impact of fasting on patients with a diagnosis of gout, finding that there were no significant differences in the incidence of either gout arthritic flares or renal colic. ${ }^{39}$

However, two studies noted that there was a significant increase $(p<0.05)$ in emergency department visits related to renal colic during the first two weeks of Ramadan. ${ }^{33,42}$ Specifically, Sagy et al. (2017) found that the increase in renal colic visits was significantly higher among Muslim patients, and that this association did not exist among non-Muslim patients. ${ }^{42}$ In both studies, temperature was controlled for either through statistical adjustment or between-group comparisons. This is an important consideration as three other studies, Basiri et al. (2004), Al Mahayni et al. (2018), and Al-Hadramy et al. (1997), noted that higher ambient temperatures were significantly associated with the number of renal stone admissions, regardless of the presence of fasting. ${ }^{35-37}$

Four studies examined metabolites and biomarkers related to fasting and renal stones. Miladipour et al. (2012) found that urine biochemistry altered significantly with fasting during Ramadan in comparison to a period before fasting. ${ }^{41}$ The authors noted decreased concentration of calcium, phosphate, and magnesium with increased concentration of uric acid, sodium, and potassium. These biochemistry changes did not translate into increased risk of calculus formation during fasting, and were noted to be largely similar between recurrent calculus formers and participants with no history of renal colic. Similarly, Cevik et al. (2016) found that Ramadan fasting increased urine density in comparison to the non-fasting period, though did not increase the number of renal stone admissions visits. ${ }^{38}$ Habib et al. (2014) found no significant changes in urea or creatinine in fasters with gout, as well as no change in renal stone incidence, in comparison to prior to fasting. ${ }^{39}$

Hodgkinson et al. (1976) was the only study that examined potential markers for stone formation outside of the context of Ramadan. ${ }^{40}$ Twelve healthy men were asked to fast for 12 hours which significantly reduced plasma uric acid levels $(p<0.001)$ in comparison to a control group. The authors therefore suggested that fasting plays a minimal role in renal stone formation, and that purine-rich foods may play a much larger role. . However, purine-rich diets were not studied and this association was made after a single fast of 12 hours. 


\section{Discussion}

To date, this is the first systematic assessment of literature regarding fasting and renal stones. Due to the varied reporting styles of the studies as well as the limited evidence base, we were unable to complete a meta-analysis on the reported outcomes. Ten studies with a total of 9906 participants were included, with participants either fasting or living in a country where fasting was a dominant cultural norm. Nine of the studies were conducted in the context of Islamic fasting during Ramadan, with the majority finding that renal colic incidence was unaffected by the month of fasting. In contrast, two studies noted an increased incidence among fasting populations. Two other studies noted that urine metabolites and density were altered with fasting. However, in those studies, the metabolite change did not translate into clinical outcomes.

Ultimately, there is limited evidence to suggest that fasting increases the risk of kidney stone formation. However, physicians should still continue to advise fasting patients to monitor water consumption to avoid dehydration. According to current guidelines, patients should attempt to produce $2.5 \mathrm{~L}$ of urine output per day, particularly if they have risk factors related for renal stone formation. ${ }^{22}$ While fasting may limit the timing of water consumption, efforts can still be made to ensure adequate intake. Discussion of other risk factors such as family history should be included in counselling. ${ }^{23}$

Our research aligns well with the current literature base related to fasting. Previous studies have noted that fasting during Ramadan is safe for patients with chronic kidney disease, as well as renal transplant patients one year post-transplant. ${ }^{24,25}$ Other studies have evaluated that fasting has not demonstrated adverse effects in patients with either type I or type II diabetes. ${ }^{26,27}$ Most religions exempt fasting for participants who are sick, pregnant, or lactating. ${ }^{28,29}$ However, it is important to note that there is limited robust clinical evidence on the long-term outcomes of intake restriction. ${ }^{30}$

As such, it is important to note several limitations of this systematic review. First, almost all studies were conducted in the context of Ramadan, with several studies limited to only men. This limits the generalizability of our findings. Second, only four studies controlled for ambient temperature, which is significantly associated with renal stone formations. Third, there were no studies that directly compared whether history of renal stones correlated with increased stone incidence while fasting. Finally, most studies were retrospective in design, rather than prospectively following a cohort. Therefore, studies may be subject to publication bias, particularly if criticisms of fasting are against cultural or social norms. ${ }^{31,32}$ Cultural and social norms may also limit the accuracy of self-reported fasting habits as participants may feel pressured to conform. Studies should ensure that data is collected in a non-judgmental manner and with full anonymity.

Included studies would be strengthened by evaluating the amount of water consumed per day. For example, for fasters who follow Ramadan, water consumption is permitted before sunrise and after sunset. This may vary significantly between participants and influence 
outcomes. Further research is needed to determine if the timing of water intake plays a role in renal stone formation independent of total water consumption.

Strengths of our review include the systematic search of three databases using a broad search strategy. Previous reviews have only conducted narrative assessments based on limited searching and inclusion criteria. In addition, our title and abstract screening was conducted in duplicate with two independent reviewers with high inter-rater agreement, which minimized the possibility of missed studies. In contrast to a non-systematic literature review, our synthesis was able to best characterize the breadth of the research while minimizing narrative biases.

The findings of this systematic review highlight three areas of future research. First, interventional trials with a control group are needed to provide high quality evidence into the risks of fasting in relation to renal stones. Second, both metabolite biomarkers and clinical outcomes should be included in future study designs. This may elucidate the biochemical mechanism linking fasting with renal stone formation Finally, variations in fasting patterns such as intermittent fasting or fasting for consecutive days should also be evaluated. This will be particularly relevant given the uptake of fasting for weight loss among the general public. While our search yielded only one study related to fasting outside of the context of Ramadan, we hope to highlight the need for additional research in this field.

\section{Conclusions}

Based on the available evidence, it is unlikely that fasting significantly increases the risk of renal stones. Physicians should counsel higher risk patients on safe fasting practices. Further high quality research is required to examine different fasting patterns and fasting in populations at high-risk for renal stone formation.

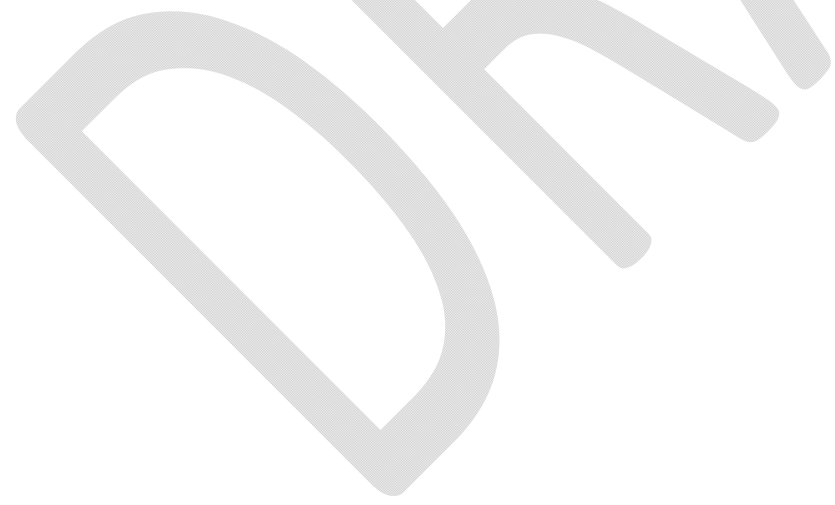




\section{References}

1. Persynaki A, Karras S, Pichard C. Unraveling the metabolic health benefits of fasting related to religious beliefs: A narrative review. Nutrition. 2017 Mar 1;35:14-20.

2. Venegas-Borsellino C, Martindale RG. From religion to secularism: the benefits of fasting. Current nutrition reports. 2018 Sep 1;7(3):131-8.

3. McKnight S. Fasting: the ancient practices. The ancient practices. In: USA: Phyllis tickle; 2010

4. https://www.bahai.org/beliefs/life-spirit/devotion/fasting

5. Julka S, Sachan A, Bajaj S, Sahay R, Chawla R, Agrawal N, Saboo B, Unnikrishnan AG, Baruah MP, Parmar G, Kalra S. Glycemic management during Jain fasts. Indian journal of endocrinology and metabolism. $2017 \mathrm{Jan} ; 21(1): 238$.

6. Peel M. Hunger strikes: Understanding the underlying physiology will help doctors provide proper advice.

7. Mattson MP, Wan R. Beneficial effects of intermittent fasting and caloric restriction on the cardiovascular and cerebrovascular systems. The Journal of nutritional biochemistry. 2005 Mar 1;16(3):129-37.

8. Dyson P. Popular diets: are they effective for people with type 2 diabetes?. Practical Diabetes. 2014 Jun;31(5):187-92.

9. Golbidi S, Daiber A, Korac B, Li H, Essop MF, Laher I. Health benefits of fasting and caloric restriction. Current diabetes reports. 2017 Dec 1;17(12):123.

10. Michalsen A. Prolonged fasting as a method of mood enhancement in chronic pain syndromes: a review of clinical evidence and mechanisms. Current pain and headache reports. 2010 Apr 1;14(2):80-7.

11. Borghi L, Meschi T, Schianchi T, Briganti A, Guerra A, Allegri F, Novarini A. Urine volume: stone risk factor and preventive measure. Nephron. 1999;81(Suppl. 1):31-7.

12. Embon OM, Rose GA, Rosenbaum T. Chronic dehydration stone disease. British journal of urology. 1990 Oct;66(4):357-62.

13. Walters D. Stress as a principal cause of calcium oxalate urolithiasis. Int Urol Nephrol 1986; 18:271-5.

14. Kalaitzidis RG, Damigos D, Siamopoulos KC. Environmental and stressful factors affecting the occurrence of kidney stones and the kidney colic. Int Urol Nephrol 2014; 46:1779-84.

15. Curhan GC, Curhan SG. Dietary factors and kidney stone formation. Comprehensive therapy. 1994;20(9):485-9.

16. Holmes RP, Assimos DG. The impact of dietary oxalate on kidney stone formation. Urological research. 2004 Oct 1;32(5):311-6.

17. Abolaban H, Al-Moujahed A. Muslim patients in Ramadan: a review for primary care physicians. Avicenna journal of medicine. 2017 Jul;7(3):81.

18. Emami-Naini A, Roomizadeh P, Baradaran A, Abedini A, Abtahi M. Ramadan fasting and patients with renal diseases: A mini review of the literature. Journal of research in medical sciences: the official journal of Isfahan University of Medical Sciences. 2013 Aug;18(8):711.

19. Shamsa A. Fasting and urinary stones. Journal of Fasting and Health. 2013;1(2):85-9. 
20. Moher D, Shamseer L, Clarke M, Ghersi D, Liberati A, Petticrew M, Shekelle P, Stewart LA. Preferred reporting items for systematic review and meta-analysis protocols (PRISMA-P) 2015 statement. Systematic reviews. 2015 Dec;4(1):1.

21. Chapter 11: Systematic Reviews - Introduction JBI Reviewer's Manual - JBI GLOBAL WIKI [Internet]. [cited 2020 March 30]. Available from: https://wiki.joannabriggs.org/display/MANUAL/1.1+Introduction+to $+\mathrm{JBI}+$ Systematic $+\mathrm{r}$ eviews

22. Türk C, Knoll T, Petrik A, et al. Guidelines on urolithiasis. Uroweb 2014; http://www.uroweb.org/guidelines/onlineguidelines/http://www.uroweb.org/guidelines/online-guidelines/

23. Krieger JN, Kronmal RA, Coxon V, et al. Dietary and behavioral risk factors for urolithiasis: potential implications for prevention. Am J Kidney Dis 1996; 28:195-201

24. Ramadan fasting and chronic kidney disease: A systematic review

25. Bernieh B, Mohamed AO, Wafa A. Ramadan fasting and renal transplant recipents: clinical and biochemical effects. Saudi J Kidney Dis Transpl 1994;5:470-3.

26. Khogeer Y, Siliman MI, Al Fayez SF. Ramadan fasting and diabetes, safety and state of control. Ann Saudi Med 1987;7(supp):6-7.

27. Bekhadir J, El Ghomari H, Klicken N, Mikou A, Sabri M. Muslims with non-insulin diabetes fasting during Ramadan: Treatment with glibenclamide. BMJ 1993;307:292-5.

28. https://bahai-library.com/pdf/s/setrakian_rosenman szucs breastfeeding.pdf

29. Bajaj S, Khan A, Fathima FN, Jaleel MA, Sheikh A, Azad K, Fatima J, Mohsin F. South Asian consensus statement on women's health and Ramadan. Indian journal of endocrinology and metabolism. 2012 Jul;16(4):508.

30. Horne BD, Muhlestein JB, Anderson JL. Health effects of intermittent fasting: hormesis or harm? A systematic review. The American journal of clinical nutrition. 2015 Aug 1;102(2):464-70.

31. Schielke S. Being good in Ramadan: ambivalence, fragmentation, and the moral self in the lives of young Egyptians. Journal of the royal anthropological institute. 2009 May;15:S24-40.

32. Ilkilic I, Ertin H. Ethical conflicts in the treatment of fasting Muslim patients with diabetes during Ramadan. Medicine, Health Care and Philosophy. 2017 Dec 1;20(4):56170 .

33. Abdolreza N, Omalbanin A, Mahdieh TS, Ali MR, Reza MS, Maryam S, Mohsen N. Comparison of the number of patients admitted with renal colic during various stages of peri-Ramadan month. Saudi Journal of Kidney Diseases and Transplantation. 2011 Nov $1 ; 22(6): 1199$.

34. Al Assaad RG, Bachir R, El Sayed MJ. Impact of Ramadan on emergency department visits and on medical emergencies. European Journal of Emergency Medicine. 2018 Dec $1 ; 25(6): 440-4$.

35. Al-Hadramy MS. Seasonal variations of urinary stone colic in Arabia. Journal-Pakistan Medical Association. 1997 Nov;47:281-3.

36. Al Mahayni AO, Alkhateeb SS, Abusaq IH, Al Mufarrih AA, Jaafari MI, Bawazir AA. Does fasting in Ramadan increase the risk of developing urinary stones?. Saudi medical journal. 2018 May;39(5):481. 
37. Basiri A, Moghaddam SM, Khoddam R, Nejad ST, Hakimi A. Monthly variations of urinary stone colic in Iran and its relationship to the fasting month of Ramadan. JournalPakistan Medical Association. 2004 Jan;54(1):6-7.

38. Cevik Y, Corbacioglu SK, Cikrikci G, Oncul V, Emektar E. The effects of Ramadan fasting on the number of renal colic visits to the emergency department. Pakistan journal of medical sciences. $2016 \mathrm{Jan} ; 32(1): 18$.

39. Habib G, Badarny S, Khreish M, Khazin F, Shehadeh V, Hakim G, Artul S. The impact of Ramadan fast on patients with gout. JCR: Journal of Clinical Rheumatology. 2014 Oct $1 ; 20(7): 353-6$.

40. Hodgkinson A. Uric acid disorders in patients with calcium stones. British journal of urology. 1976 Feb;48(1):1-5.

41. Miladipour AH, Shakhssalim N, Parvin M, Azadvari M. Effect of Ramadan fasting on urinary risk factors for calculus formation.

42. Sagy I, Zeldetz V, Halperin D, Abu Tailakh M, Novack V. The effect of Ramadan fast on the incidence of renal colic emergency department visits. QJM: An International Journal of Medicine. 2017 Sep 1;110(9):571-6.

43. Kim SY, Park JE, Lee YJ, Seo HJ, Sheen SS, Hahn S, Jang BH, Son HJ. Testing a tool for assessing the risk of bias for nonrandomized studies showed moderate reliability and promising validity. Journal of clinical epidemiology. 2013 Apr 1;66(4):408-14.

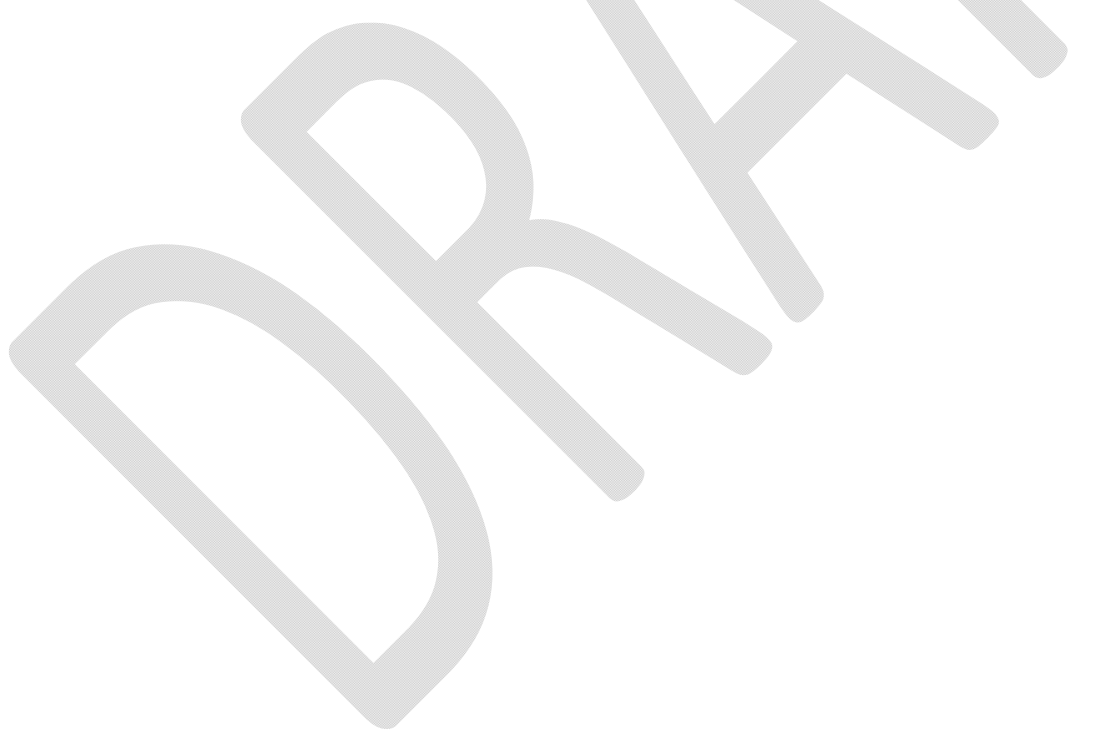




\section{Figures and Tables}

Fig. 1. PRISMA diagram of study screening process.

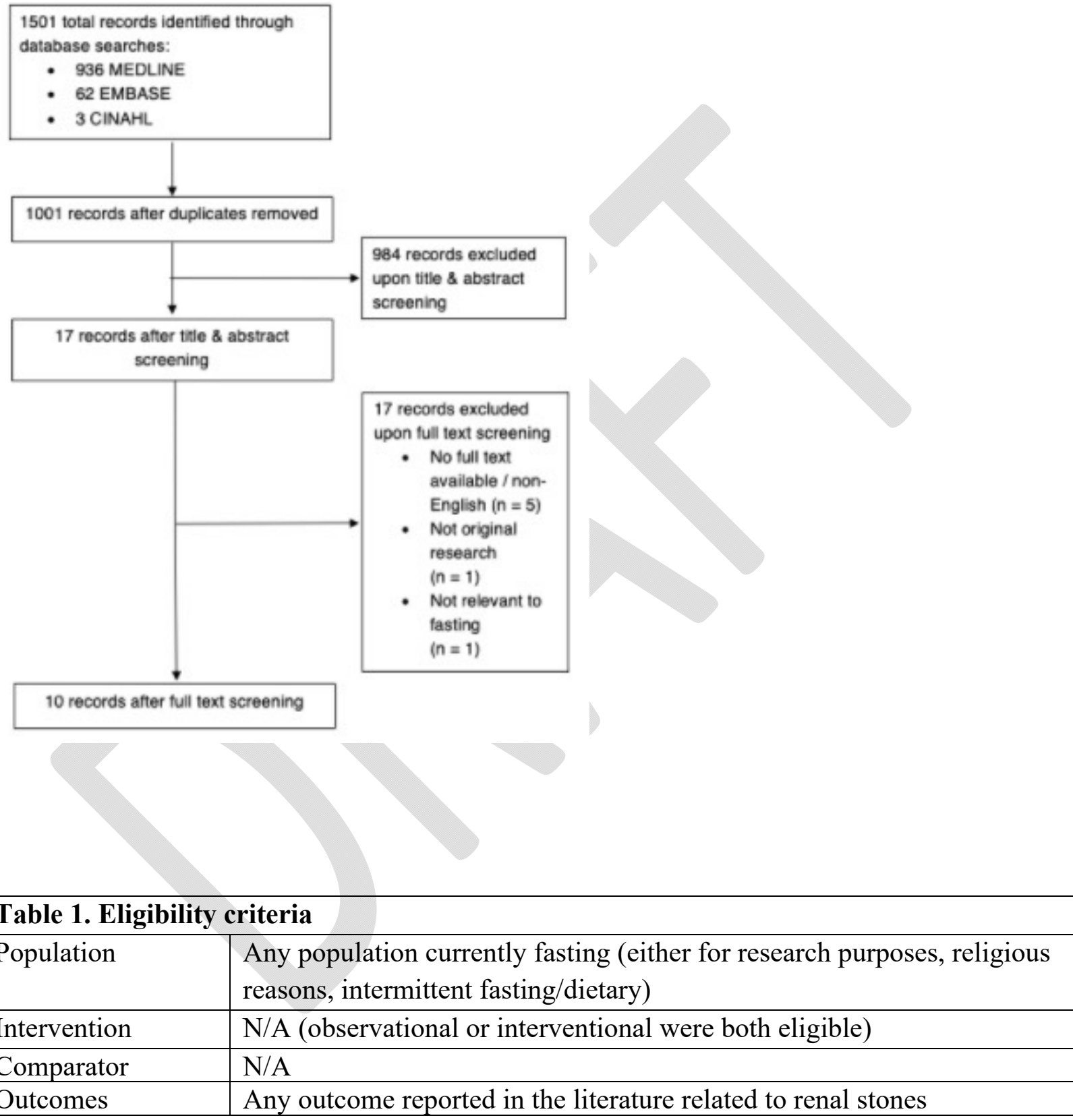




\begin{tabular}{|c|c|c|c|c|c|c|}
\hline Citation, country & Study design & $\begin{array}{l}\text { Type of } \\
\text { fasting }\end{array}$ & $\begin{array}{l}\text { Sample } \\
\text { size }\end{array}$ & $\begin{array}{l}\text { Mean } \\
\text { age } \\
\text { (SD) }\end{array}$ & $\begin{array}{l}\text { Sex } \\
(\mathbf{M} / \mathbf{F})\end{array}$ & Summary of key outcome \\
\hline $\begin{array}{l}\text { Abdolreza 2011, } \\
\operatorname{Iran}^{33}\end{array}$ & $\begin{array}{l}\text { Prospective } \\
\text { observational }\end{array}$ & Ramadan & 610 & 37.6 & $441 / 169$ & $\begin{array}{l}\text { Admissions due to renal colic } \\
\text { were higher during the first two } \\
\text { weeks of Ramadan }(p<0.05)\end{array}$ \\
\hline $\begin{array}{l}\text { Al Assaad 2018, } \\
\text { Lebanon }^{34}\end{array}$ & $\begin{array}{l}\text { Prospective } \\
\text { observational }\end{array}$ & Ramadan & 3536 & 54.1 & $2041 / 1495$ & $\begin{array}{l}\text { No change in renal colic } \\
\text { incidence in Ramadan months } \\
(\mathrm{p}=0.615)\end{array}$ \\
\hline $\begin{array}{l}\text { Al-Hadramy } 1997, \\
\text { Saudi Arabia }\end{array}$ & Retrospective & Ramadan & NR & & All male & $\begin{array}{l}\text { No change in renal colic } \\
\text { incidence in Ramadan months } \\
(\mathrm{p}=0.223)\end{array}$ \\
\hline $\begin{array}{l}\text { Al Mahayni 2018, } \\
\text { Saudi Arabia }\end{array}$ & $\begin{array}{l}\text { Retrospective } \\
\text { observational }\end{array}$ & Ramadan & 237 & 458 & $178 / 59$ & $\begin{array}{l}\text { No change in renal colic } \\
\text { incidence in Ramadan months } \\
(\mathrm{p}=0.599)\end{array}$ \\
\hline Basiri 2004, $\operatorname{Iran}^{37}$ & $\begin{array}{l}\text { Retrospective } \\
\text { observational }\end{array}$ & Ramadan & 574 & 36.4 & $398 / 173$ & $\begin{array}{l}\text { No change in renal colic } \\
\text { incidence in Ramadan months } \\
(\mathrm{p}=0.32)\end{array}$ \\
\hline $\begin{array}{l}\text { Cevik 2016, } \\
\text { Pakistan }^{38}\end{array}$ & $\begin{array}{l}\text { Prospective } \\
\text { observational }\end{array}$ & Ramadan & 176 & 40.5 & $112 / 64$ & $\begin{array}{l}\text { Fasting in Ramadan does not } \\
\text { change the number of renal colic } \\
\text { visits, although fasting during } \\
\text { Ramadan was associated with } \\
\text { increased urine density and } \\
\text { decreased WBC count }\end{array}$ \\
\hline Habib 2014, U.S. ${ }^{39}$ & $\begin{array}{l}\text { Prospective } \\
\text { observational }\end{array}$ & Ramadan & 43 & 51 & $41: 2$ & $\begin{array}{c}\text { No significant difference } \\
\text { between groups fasting and not } \\
\text { fasting for renal stone incidence } \\
\text { ( } 0 \text { stones in cohort })\end{array}$ \\
\hline Hodgkinson et $\mathrm{al}^{40}$ & $\begin{array}{c}\text { Prospective } \\
\text { observational }\end{array}$ & $\begin{array}{l}\text { Fasting for } \\
12 \text { hours }\end{array}$ & 156 & $20-55$ & All male & $\begin{array}{l}\text { Lower uric acid levels were } \\
\text { found in healthy patients }\end{array}$ \\
\hline Miladipour et $\mathrm{al}^{41}$ & $\begin{array}{l}\text { Prospective } \\
\text { observational }\end{array}$ & Ramadan & 57 & $30-55$ & All male & $\begin{array}{l}\text { Urine biochemistry varied } \\
\text { significantly during fasting with } \\
\text { decrease in the concentration of } \\
\text { certain electrolytes (calcium, } \\
\text { phosphate, magnesium) while } \\
\text { certain electrolytes increased } \\
\text { (uric acid, and potassium). These } \\
\text { biochemistry changes were } \\
\text { similar between recurrent }\end{array}$ \\
\hline
\end{tabular}




\begin{tabular}{|c|c|c|c|c|c|c|}
\hline & & & & & & $\begin{array}{l}\text { calculus formers and participants } \\
\text { with no history of renal colic, } \\
\text { with the exception of serum } \\
\text { sodium, which was significantly } \\
\text { lower in the calculus former } \\
\text { group while fasting. However, } \\
\text { this did not translate into } \\
\text { increased risk of calculus } \\
\text { formation during fasting for } \\
\text { either group. }\end{array}$ \\
\hline Sagy et al ${ }^{42}$ & Retrospective & Ramadan & 4517 & 37.9 & $3446 / 1071$ & $\begin{array}{c}\text { There was an increase in renal } \\
\text { colic related ED visits during the } \\
\text { first } 2 \text { weeks of Ramadan (RR } \\
1.267,95 \% \text { CI } 1.031-1.502) \\
\text { among Muslims but not among } \\
\text { Jews (1.061, 95\% CI 0.885- } \\
1.238) .\end{array}$ \\
\hline
\end{tabular}

CI: confidence interval; ED: emergency department; RR: relative risk; SD: standard deviation; WBC: white blood cell.

Table 3. Risk of bias assessment

\begin{tabular}{|l|c|c|c|c|c|c|c|}
\hline Study & Year & $\begin{array}{c}\text { Participant } \\
\text { selection }\end{array}$ & Confounding & $\begin{array}{c}\text { Measurement } \\
\text { of exposure }\end{array}$ & Blinding & $\begin{array}{c}\text { Incomplete } \\
\text { outcome data }\end{array}$ & Total \\
\hline Abdolreza et al $^{33}$ & 2011 & 1 & 1 & 1 & 1 & 1 & 5 \\
\hline Al Assaad et al $^{34}$ & 2018 & 2 & 1 & 2 & 1 & 1 & 7 \\
\hline Al-Hadramy et al $^{35}$ & 1997 & 1 & 1 & 2 & 1 & 1 & 6 \\
\hline Al Mahayni et al $^{36}$ & 2018 & 1 & 1 & 2 & 1 & 1 & 6 \\
\hline Basiri et al $^{37}$ & 2004 & 1 & 1 & 2 & 1 & 1 & 6 \\
\hline Cevik et al $^{38}$ & 2016 & 2 & 2 & 2 & 1 & 1 & 8 \\
\hline Habib et al $^{39}$ & 2014 & 1 & 1 & 1 & 1 & 1 & 5 \\
\hline Hodgkinson et al $^{40}$ & 1976 & 1 & 1 & 1 & 1 & 1 & 5 \\
\hline Miladipour et al $^{41}$ & 2012 & 1 & 1 & 1 & 1 & 1 & 5 \\
\hline Sagy et al $^{42}$ & 2017 & 2 & 2 & 2 & 1 & 1 & 8 \\
\hline
\end{tabular}

Adapted from the RoBANS tool. ${ }^{43}$ A score of "1" indicates low-risk, " 2 " indicates high-risk, and "0" is unclear. 


\begin{tabular}{|l|l|}
\hline \multicolumn{2}{|l|}{ Supplementary Table 1. Search strategy (adapted for Embase and CINAHL) } \\
\hline$\#$ & Searches \\
\hline 1 & $(($ (renal OR kidney OR urin*) adj1 (stone* or calcul* or colic*)).ti,ab. \\
\hline 2 & (nephrolith* OR urolithiasis*).ti,ab. \\
\hline 3 & 1 OR 2 \\
\hline 4 & (fast* OR Ramadan*).ti,ab. \\
\hline 5 & 3 AND 4 \\
\hline
\end{tabular}

Database: Ovid MEDLINE: Epub ahead-of-print, in-process, and other non-indexed citations from Ovid MEDLINE ${ }^{\circledR}$ Daily and Ovid MEDLINE ${ }^{\circledR} 1946$ to March 18, 2020. 